\title{
Knowledge as a Predictor of Insurance Coverage Under the Affordable Care Act
}

\author{
Maximiliane Hoerl, MSc, * Amelie Wuppermann, PhD, ${ }^{*}$ Silvia H. Barcellos, PhD, $\dagger$ \\ Sebastian Bauhoff, PhD, $\$$ Joachim K. Winter, PhD, ${ }^{*}$ and Katherine G. Carman, PhD $\S$
}

\begin{abstract}
Background: The Affordable Care Act established policy mechanisms to increase health insurance coverage in the United States. While insurance coverage has increased, $10 \%-15 \%$ of the US population remains uninsured.
\end{abstract}

Objectives: To assess whether health insurance literacy and financial literacy predict being uninsured, covered by Medicaid, or covered by Marketplace insurance, holding demographic characteristics, attitudes toward risk, and political affiliation constant.

Research Design: Analysis of longitudinal data from fall 2013 and spring 2015 including financial and health insurance literacy and key covariates collected in 2013.

Subjects: A total of 2742 US residents ages 18-64, 525 uninsured in fall 2013, participating in the RAND American Life Panel, a nationally representative internet panel.

Measures: Self-reported health insurance status and type as of spring 2015 .

Results: Among the uninsured in 2013, higher financial and health insurance literacy were associated with greater probability of being insured in 2015. For a typical uninsured individual in 2013, the probability of being insured in 2015 was 8.3 percentage points higher with high compared with low financial literacy, and 9.2 percentage points higher with high compared with low health insurance literacy. For the general population, those with high financial and health insurance literacy were more likely to obtain insurance through Medicaid or the Marketplaces compared with

From the *Department of Economics, University of Munich, Munich, Germany; †Center for Economic and Social Research, University of Southern California, Los Angeles, CA; \$Center for Global Development, Washington, DC; and §The RAND Corporation, Santa Monica, CA.

Supported by grants R21-AG044737 and 5P30AG024962 from the National Institute on Aging and by the Bing Center for Health Economics at the RAND Corporation.

Part of this research was conducted while M.H. was visiting the University of Southern California.

The authors declare no conflict of interest.

Reprints: Katherine G. Carman, PhD, The RAND Corporation, 1776 Main Street, P.O. Box 2138, Santa Monica, CA 90407-2138. E-mail: kcar man@rand.org.

Supplemental Digital Content is available for this article. Direct URL citations appear in the printed text and are provided in the HTML and PDF versions of this article on the journal's Website, www.lww-medical care.com.

Copyright (C) 2016 Wolters Kluwer Health, Inc. All rights reserved.

ISSN: 0025-7079/17/5504-0428 being uninsured. The magnitude of coefficients for these predictors was similar to that of commonly used demographic covariates.

Conclusions: A lack of understanding about health insurance concepts and financial illiteracy predict who remains uninsured. Outreach and consumer-education programs should consider these characteristics.

Key Words: Affordable Care Act, health insurance, health policy, demand for insurance

(Med Care 2017;55: 428-435)

$T$ he Affordable Care Act (ACA) of 2010 introduced multiple policy mechanisms designed to increase health insurance coverage in the United States. First, it offered incentives for states to expand Medicaid to low-income groups. Second, it introduced health insurance Marketplaces to facilitate enrollment and create competition across insurers. Third, it subsidized the purchase of insurance in the Marketplaces for those with incomes between 100\% (effectively $138 \%$ in Medicaid expansion states) and $400 \%$ of the Federal Poverty Level. Finally, it established a penalty for those who opt to remain uninsured, with some exemptions. Although surveys estimate that the rate of insurance coverage among adults age 18-64 increased by $4-8$ percentage points since 2013 , they also estimate that $10 \%-15 \%$ of the US population remains uninsured. ${ }^{1-8}$ This lingering gap suggests that important impediments to further increasing insurance enrollment may persist.

Previous research on insurance choices following the first ACA open enrollment has focused on sociodemographic characteristics, finding, for example, that lower educational and income levels and being Hispanic are associated with being uninsured, and that people who live in states that did not expand Medicaid are also likely to remain uninsured. ${ }^{1-3,5-8}$ Perceptions that premiums for insurance in the Marketplace are too high may also limit the total impact that the ACA has on uninsurance rates. However, there are potentially other unrecognized factors that may influence choices about health insurance. Financial literacy (defined as knowledge about financial concepts) and attitudes toward risk, for instance, have been found to play an important role in other financial decisions. ${ }^{9-12}$ It seems likely that they would influence decisions about health insurance as well. Similarly, limits in knowledge about health insurance concepts, such as deductibles or copayments, may limit some 
consumers' ability to evaluate whether the benefits of health insurance exceed its costs.

In this paper, we turn the lens onto these potential impediments to further decreasing the number who are uninsured and to enrollment in Medicaid and Marketplace insurance, investigating whether health insurance transitions are associated with health insurance literacy (defined as knowledge of health insurance concepts) and financial literacy. Furthermore, our data allow us to control for levels of risk aversion and political leanings, which may also predict uptake of insurance but are not typically available in surveys about health insurance. Unlike most previous research on this topic, we made use of rich longitudinal data, acquired from the nationally representative RAND American Life Panel (ALP), that offer information on more of the potential impediments to enrollment than datasets used in earlier studies. In particular, we made use of a new measure of health insurance literacy documented in previous work ${ }^{13}$ and assessed whether knowledge is associated with health insurance coverage. With access to these data, we could analyze the role of these variables, along with those of traditional sociodemographic insurance predictors. A key strength of this research design is the use of longitudinal data enabling us to investigate how these factors were related to individual-level changes in insurance coverage over time. Notably, the data allowed us to measure these characteristics before the ACA Marketplace's first open enrollment period in 2013, ensuring that enrollment decisions made after the rollout of the Marketplaces did not impact our measures of knowledge. Furthermore, by collecting data about respondents' current insurance status, we avoided recall bias. Other studies assessing these effects used cross sectional data, lacked the rich set of covariates, or focused on samples not representative of the general population. ${ }^{14}$

\section{METHODS}

\section{Data Sources and Study Sample}

The ALP is a nationally representative internet panel of respondents who participate in occasional online surveys. Panel members without internet access are provided with a computer and an internet connection, eliminating the bias found in many internet surveys, which include only existing computer users (https://alpdata.rand.org/). We calculated sample weights to make the distributions of age, sex, ethnicity, education, income, and household size approximate the distributions in the Census Bureau's Current Population Survey (CPS). ${ }^{15}$ Panel members have been recruited over time, through several different mechanisms. The cumulative response rate across all recruitment waves is approximately $9 \%$. While this is low, it is similar to other nationally representative surveys conducted by nongovernmental organizations. Furthermore, ALP estimates of the uninsured rate among working-age adults in 2013 and 2014 (2013: 20.3\%; 2014: $13.7 \%)^{16}$ are similar to those from the CPS (2013: $18.5 \%$; $201414.3 \%) .^{7}$ The ALP has produced accurate predictions in other settings as well, notably the 2012 Presidential Election. ${ }^{17}$
Our analyses focused on 2742 respondents age 18-64 who completed surveys in fall 2013 (baseline) and spring 2015 (follow-up). We conducted our baseline survey from August 23 to September 30, 2013, just before the first openenrollment period for the Marketplaces. We fielded our follow-up survey from March 1 to May 26, 2015. In total, 84 $\%$ of those answering the baseline survey also responded to the follow-up. Both surveys included questions about health insurance literacy and coverage (Supplemental Digital Content 1, http://links.lww.com/MLR/B311). Measures of risk aversion and financial literacy were collected between September 20, 2013 and March 5, 2014. Information about political affiliation was collected in earlier ALP surveys fielded by other researchers before our baseline survey. This information was missing for approximately $28 \%$ of respondents who were not previously asked about their political affiliation. We focused on respondents who answered all questions included in our analysis constituting $92 \%$ of those who completed both surveys (except those about political affiliation where we included an indicator if this information was missing).

\section{Outcome Measures}

At both baseline and follow-up, we collected data about whether the respondent currently had health insurance, and if so, what type-Employer Sponsored Insurance, Medicaid, insurance through a Marketplace, or insurance through other sources (eg, privately purchased nongroup insurance, Medicare, Military or Veterans insurance, insurance from other small state programs). Employer Sponsored Insurance includes coverage obtained through COBRA, the survey respondent's employer, or the employer of the respondent's spouse or parent. The rates of uninsurance, enrollment in Medicaid, and enrollment via the Marketplaces that we estimated from these data were similar to rates measured in other studies, ${ }^{1-4}$ as well as to estimates from the Centers for Medicare and Medicaid Services, the Department of Health and Human Services, and the Census Bureau. ${ }^{7,18,19}$

\section{Independent Variables of Interest}

We focused on 2 predictors of insurance coverage, both measured at baseline. First, we collected standard measures of financial literacy covering fundamental concepts of economics and finance which have been shown to affect complex financial decisions, including retirement planning and stock market participation. ${ }^{9,10}$ The questions measure basic knowledge of interest rates (numeracy), inflation, and the safety of stocks versus bonds (risk). We classified individuals as having high financial literacy if they correctly answered all 3 questions. ${ }^{10,11}$ Previously research has found that financially literate individuals are better at making financial decisions and avoiding negative financial consequences. ${ }^{9,10}$ Individuals who are less financially literate may have more difficulties or feel less confident making decisions about health insurance, which aims to shield individuals from uncertain, potentially large financial consequences related to medical expenditures. 
Second, we measured health insurance literacy [7 questions about deductibles, co-pays, coinsurance, networks, and prescription drug pricing (generic vs. brand name)]. ${ }^{20}$ These questions reflect individual knowledge of health insurance concepts, which are the factors that distinguish health insurance plans. These factors are likely to be important to anyone who has a choice in health insurance plans, especially those who have many plans to compare in the Marketplaces. Knowledge of these concepts is thus likely to be important for choosing health insurance ${ }^{21}$-and making good choices. ${ }^{22}$ We classified individuals as having low health insurance literacy if they correctly answered fewer than 3 of the 7 questions. This presents a rather low bar and captures individuals with potentially limited experience with health plans which is likely to be the case for the previously uninsured. Individuals with lower health insurance or financial literacy may be less likely to purchase insurance, because of difficulties in fully considering costs and benefits of different products when comparing insurance products in the complex environment. ${ }^{23,24}$ More information on these variables is provided in an online appendix.

\section{Covariates}

We controlled for demographic characteristics collected at baseline, including sex, age, race and ethnicity, education, household income, employment status, family status, and health. We also included an indicator for whether or not the respondent's state of residence expanded Medicaid. We obtained similar results from alternative specifications controlling for whether the states had state-based Marketplaces, the states' leaning in the 2012 presidential election, or using state-fixed effects.

In addition to these more commonly used demographic variables, we also controlled for risk aversion and political preference. We measured risk aversion, defined as one's willingness to take risks (measured on a $0-10$ scale). We classified individuals as having either a high (less willing to take risks) or low (more willing to take risks) aversion to risk by splitting them at the median. Prior research has shown the behavioral validity of this measure using paid lottery choices. ${ }^{25}$ Those who are more risk averse may be more likely to demand health insurance. ${ }^{26}$ Finally, we included political affiliation prior to baseline. Public opinion of the ACA is divided strongly along party lines, with Republicans often opposing the $\mathrm{ACA}^{27-29}$ and showing lower intentions to comply with the individual mandate. ${ }^{30}$ Republicans may consequently be less likely to take advantage of Medicaid or the Marketplaces, leading to lower levels of insurance coverage. Previous research has been inconclusive on this issue. $^{31}$

\section{Statistical Analysis}

We analyzed 2 populations in 2 separate sets of analyses: respondents uninsured at baseline and all respondents, regardless of initial insurance status. For those uninsured at baseline, we calculated the fraction who obtained insurance by spring 2015 by various demographic characteristics. For both populations, we separately estimated logit regressions to model the predicted probability of having insurance at follow-up (ie, the choice to become insured), and multinomial logit regressions to model the predicted probability of selecting different types of insurance (ie, Medicaid, the Marketplaces, or through their employers) in comparison with being uninsured. To account for possible correlation between different factors that influence insurance take-up or choice of type of insurance, we include the above-mentioned control variables. The results can thus be interpreted as changes in insurance status or type related to levels of knowledge when holding the other factors constant. We report odds ratios (OR) for logit regressions and relative risk ratios (RRR) for multinomial logit regressions. We also interpret the results in terms of marginal effects. We used heteroscedasticity-adjusted SE clustered at the state of residence. We conducted our analyses using Stata $14 .{ }^{32}$ In the multinomial regressions for the full sample, we controlled for the type of insurance individuals had at baseline, as individuals who had insurance in 2013 were likely to have the same type of insurance at follow-up.

\section{RESULTS}

\section{Descriptive Statistics}

Columns 1,3 , and 5 of Table 1 provide summary statistics for the full sample and those uninsured and insured at baseline while columns 2, 4, and 6 provide them for the March 2013 CPS. Our weighted ALP survey sample tracks the distribution of key covariates in the broader, nationally representative CPS sample, including for variables that were not used to construct the statistical weights. In total, $54 \%$ of our sample had low financial literacy; $12 \%$, low health insurance literacy. Both numbers were higher among those uninsured compared with those insured at baseline. The correlation between the 2 variables is 0.271 among the general population and 0.268 among the uninsured (both $P<0.001$ ). Table 1 in the online appendix (Supplemental Digital Content 2, http://links.lww.com/MLR/B312), shows summary statistics by source of insurance.

\section{Insurance Coverage Among the Previously Uninsured}

In this section we investigate who gained insurance, focusing on enrollment in Medicaid and Marketplace insurance among the previously uninsured. Figure 1 displays the insurance status of respondents uninsured at baseline, by our key variables of interest. Overall, $60.2 \%$ of this group had obtained insurance by spring 2015 . Those with lower levels of financial and health insurance literacy were less likely to have obtained coverage. Figure 1 in the online appendix, Supplemental Digital Content 3 (http://links. lww.com/MLR/B313), shows that in the bivariate analysis the more risk averse, Republicans, Hispanics, the less educated, larger households, those with lower health expenditures, and those living in states that opted not to expand Medicaid were less likely to have obtained insurance by spring 2015 (all $P<0.05$ ).

Table 2, column 1 presents the results from the logit regression modelling the predicted probability that those uninsured at baseline have insurance at follow-up. We found 
TABLE 1. Descriptive Statistics

$\begin{array}{ccccccc} & \text { American Life } & \text { Current Population } & \text { American Life } & \text { Current Population } & \text { American Life } & \text { Current Population } \\ \text { Characteristics } & \text { Panel }(n=2742) & \text { Survey }(n=122,316) & \text { Panel }(n=525) & \text { Survey }(n=24,523) & \text { Panel }(n=2217) & \text { Survey }(n=97,793)\end{array}$

Health insurance in fall $2013(\%)$

Uninsured

Medicaid

ESI

All other

Literacy (\%)

Low financial

literacy

High financial

literacy

Low health

insurance literacy

High health insurance literacy

Risk attitude (\%)

Low risk aversion

High risk aversion

Political affiliation (\%)

Democrat

Republican

Other party/

Independent

Missing party

affiliation

Sex (\%)

Male

Female

Age (\%) (y)

Younger than 26

26-44

45 and older

Race and ethnicity (\%)

Non-Hispanic white

Non-Hispanic

nonwhite

Hispanic

Education (\%)

No degree

High school or

equivalent

Some college

Associate degree

Bachelor's degree and more

Income (\%)

Income lower than

138 of FPL

Income 138-250 of FPL

Income $251-400$ of FPL

Income higher than 400 of FPL

Employment (\%)

Employed 2013/

2015

Unemployed 2013/

2015

Employed 2013/

unemployed 2015

Unemployed 2013/

employed 2015

00
0
0


TABLE 1. Descriptive Statistics (continued)

\begin{tabular}{|c|c|c|c|c|c|c|}
\hline \multirow[b]{2}{*}{ Characteristics } & \multicolumn{2}{|c|}{ Full Sample } & \multicolumn{2}{|c|}{ Uninsured } & \multicolumn{2}{|c|}{ Insured } \\
\hline & $\begin{array}{c}\text { American Life } \\
\text { Panel }(\mathrm{n}=\mathbf{2 7 4 2})\end{array}$ & $\begin{array}{c}\text { Current Population } \\
\text { Survey }(\mathrm{n}=122,316) \\
\end{array}$ & $\begin{array}{c}\text { American Life } \\
\text { Panel }(n=525)\end{array}$ & $\begin{array}{c}\text { Current Population } \\
\text { Survey }(\mathrm{n}=\mathbf{2 4 , 5 2 3 )}\end{array}$ & $\begin{array}{c}\text { American Life } \\
\text { Panel }(n=2217)\end{array}$ & $\begin{array}{r}\text { Current Population } \\
\text { Survey }(\mathrm{n}=97,793) \\
\end{array}$ \\
\hline Married & 64 & 61 & 48 & 49 & 68 & 64 \\
\hline $\begin{array}{l}3 \text { and less other } \\
\text { household } \\
\text { members }\end{array}$ & 84 & 83 & 80 & 80 & 85 & 84 \\
\hline \multicolumn{7}{|l|}{ Health $(\%)$} \\
\hline $\begin{array}{l}\text { Excellent/very } \\
\text { good/good health }\end{array}$ & 87 & 89 & 80 & 88 & 89 & 89 \\
\hline Fair/poor health & 13 & 11 & 20 & 12 & 11 & 11 \\
\hline $\begin{array}{l}\text { Health expenditures } \\
\text { (last } 4 \text { mo): } \\
\leq \$ 100\end{array}$ & 67 & $*$ & 74 & $*$ & 65 & $*$ \\
\hline Medicaid expansion & 56 & 50 & 52 & 45 & 57 & 51 \\
\hline $\begin{array}{l}\text { The weighted averages } \\
\text { individuals participating pr } \\
\text { *No comparable inforn } \\
\text { 'Most recent indicated } \\
\text { ESI indicates Employe } \\
\text { Sources: Fall 2013 RA }\end{array}$ & $\begin{array}{l}\text { s for individuals youn } \\
\text { rior to October } 2013 \mathrm{w} \\
\text { mation available in } \mathrm{Cu} \\
\text { political affiliation in } \\
\text { er Sponsored Insurance } \\
\text { AND American Life Pa }\end{array}$ & $\begin{array}{l}\text { ger than } 65 \text { with nonmissing } \\
\text { ith valid health insurance inf } \\
\text { rrent Population Survey. } \\
\text { American Life Panel, missin } \\
\text {; FPL. Federal Poverty Leve } \\
\text { inel and March } 2013 \text { Current }\end{array}$ & $\begin{array}{l}\text { values in the baselin } \\
\text { formation in fall } 2013 \\
\text { g for some participant } \\
\text { Population Survey, in }\end{array}$ & $\begin{array}{l}\text { le dimensions. The Americ } \\
\text { and spring } 2015 \text {. } \\
\text { ts. } \\
\text { dividuals aged } 18-64 \text {. }\end{array}$ & an Life Panel samples & \\
\hline
\end{tabular}

significant associations with the probability of obtaining insurance for our key independent variables: Those with high financial $[\mathrm{OR}=1.429 ; 95 \%$ confidence interval $(\mathrm{CI})$, $0.934-2.185)$ or health insurance literacy $(\mathrm{OR}=1.464 ; 95 \%$ CI, 1.025-2.093) were more likely to gain insurance than those with low literacy.

The magnitude of the effects of financial and health insurance are large relative to key covariates. Take a typical

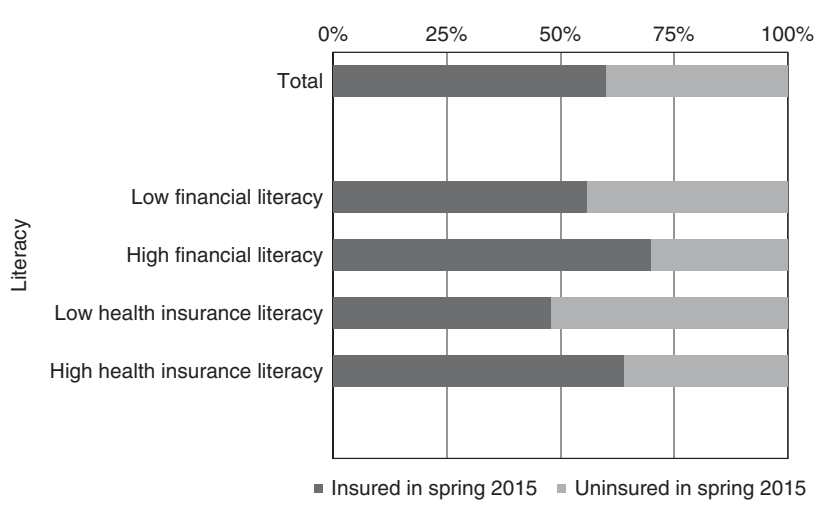

FIGURE 1. Insurance status in spring 2015 for individuals uninsured in fall 2013 by knowledge and preferences. The share of prior uninsured individuals obtaining health insurance between fall 2013 and spring 2015 by literacy, risk attitude, and political affiliation $(n=525)$. Source: RAND American Life Panel, individuals aged 18-64. individual without health insurance in 2013. The probability they had health insurance in 2015 was 8.3 percentage points higher if this individual had high instead of low financial literacy. Moreover, it was an additional 9.2 percentage points higher if this individual had high instead of low health insurance literacy. In comparison, having attended at least some college (or more) in comparison to having no degree was associated with a 20-22 percentage point increase in the probability to have insurance in 2015 . This shows that a large fraction of this college advantage can be offset by having high financial and health insurance literacy (together 17.5 percentage points) and that financial and health insurance literacy matter for insurance choice above and beyond formal education. Furthermore, the probability of having health insurance in 2015 decreases by 13.1 percentage points for those losing employment between 2013 and 2015 in comparison with those staying employed during that period.

Columns $2-5$ in Table 2 report the results of the multinomial logit regression investigating in what types of insurance respondents enrolled in, compared with being uninsured. The uninsured with high financial literacy were more likely to obtain insurance from the Marketplaces compared to staying uninsured $(\mathrm{RRR}=1.862 ; 95 \% \mathrm{CI}$, 0.963-3.603). Those with high health insurance literacy tended to obtain insurance from other sources, besides Medicaid, the Marketplace, or employer insurance $(\mathrm{RRR}=$ $1.803, ; 95 \%$ CI, 1.160-2.801).

Table 2 in the online appendix (Supplemental Digital Content 4, http://links.lww.com/MLR/B314), presents the 
TABLE 2. Characteristics Associated With Coverage and Selection of Health Insurance for Individuals Uninsured in Fall 2013

\begin{tabular}{|c|c|c|c|c|c|}
\hline & \multirow{3}{*}{$\begin{array}{c}\text { Any Coverage } \\
\text { Logit }(95 \% \text { CI }) \\
(n=525)\end{array}$} & \multicolumn{4}{|c|}{ Type of Coverage Selected } \\
\hline & & \multicolumn{4}{|c|}{ Multinomial Logit $(95 \%$ CI $)(n=525)$} \\
\hline & & $\begin{array}{c}\text { Medicaid } \\
(n=71)\end{array}$ & $\begin{array}{c}\text { Marketplace } \\
(n=56)\end{array}$ & $\begin{array}{c}\text { ESI } \\
(n=100)\end{array}$ & $\begin{array}{l}\text { All Other } \\
(n=89)\end{array}$ \\
\hline \multicolumn{6}{|l|}{ Literacy } \\
\hline High financial literacy & $1.429(0.934-2.185)^{*}$ & $1.793(0.794-4.049)$ & $1.862(0.963-3.603)^{*}$ & $1.355(0.812-2.262)$ & $1.332(0.648-2.738)$ \\
\hline High health insurance literacy & $1.464(1.025-2.093)^{* *}$ & $1.404(0.713-2.766)$ & $1.543(0.658-3.617)$ & $1.277(0.651-2.504)$ & $1.803(1.160-2.801)^{* * *}$ \\
\hline Pseudo- $R^{2}$ & 0.1101 & 0.1724 & & & \\
\hline \multicolumn{6}{|c|}{$\begin{array}{l}\text { The odds ratios ( } 95 \% \text { CIs) from logistic regression (column } 1) \text { and relative risk ratios }(95 \% \text { CIs) from multinomial logistic regression (columns } 2-5) \text { using heteroscedasticity- } \\
\text { adjusted SEs clustered at the state of residence level. Regressions further include controls for gender, age, race and ethnicity, education, income, employment and family status, } \\
\text { health and state characteristics, risk aversion, and political affiliation. Results in these dimensions are presented in online appendix Table } 2 \text {. } \\
\text { CI indicates confidence interval; ESI, Employer Sponsored Insurance } \\
\quad * P<0.10 \text {. } \\
\quad * * P<0.05 \text {. } \\
\quad * * * P<0.01 \text {. } \\
\text { Source: RAND American Life Panel, individuals aged } 18-64 \text {. }\end{array}$} \\
\hline
\end{tabular}

findings for the demographic controls in the regressions including gender, age, race and ethnicity, education, income, employment and family status, health and state characteristics. The coefficients for these predictors are in line with earlier studies. In addition, it presents results for risk aversion and political leaning. Among the previously uninsured, risk averse individuals are more likely to obtain insurance and Republicans are less likely to obtain insurance.

\section{Insurance Coverage Among the General Population}

In this section we investigate how insurance coverage changed following the introduction of the ACA Marketplaces, focusing on enrollment in Medicaid and Marketplace insurance among both the previously uninsured and the previously insured. Table 3, column 1 shows who among our full sample had insurance coverage at follow-up. Those with high financial and health insurance literacy were each more likely $(\mathrm{OR}=1.598 ; 95 \% \mathrm{CI}, 1.142-2.234$ and $\mathrm{OR}=1.537$; $95 \% \mathrm{CI}, 1.221-1.933$, respectively) to have insurance in 2015 than those with low literacy.

Take a typical individual regardless of insurance status in 2013. The probability they had health insurance in 2015 is 1.6 percentage points higher for individuals with high instead of low financial literacy and by 1.7 percentage points for those with high instead of low health insurance literacy. Those with high financial and high health insurance literacy are thus 3.3 percentage points more likely to have insurance, which is similar to the calculated marginal effect of having a bachelor's degree (or more) relative to no degree, 3.3 percentage points, or living in a Medicaid expansion state, 3.1 percentage points higher.

In the multinomial logit (Table 3, columns 2-5), those with high levels of financial or health insurance literacy were more likely $(\mathrm{RRR}=2.140 ; 95 \% \mathrm{CI}, 1.381-3.316$ and $\mathrm{RRR}=1.987,95 \% \mathrm{CI}, 1.146-3.447$, respectively) to be covered via the Marketplaces. Those who in 2015 were covered through employers and the Marketplaces had the highest levels of financial and health insurance literacy in 2013 (Fig. 2).
Table 3 in the online appendix (Supplemental Digital Content 5, http://links.lww.com/MLR/B315), presents the findings for the demographic controls, risk aversion, and political leaning in the regressions, which are consistent with other studies.

\section{CONCLUSIONS}

When looking at the decisions of Americans about health insurance in the context of the ACA, it is important to consider not just individuals who were uninsured before 2014, when key provisions of the legislation rolled out, but also the general population, as a number of those who chose to enroll in Medicaid and through the Marketplaces already had coverage in $2013 .{ }^{4}$ In this study, we were able to look at each of these populations and our dataset enabled us to investigate a wider set of characteristics than other research has done to date. We found that knowledge variables that until now have been unrecognized - health insurance literacy and financial literacy-did, indeed, appear to play a role in the health-insurance choices of our sample between 2013 and 2015. Furthermore, these effects hold even after controlling for other important determinants of insurance coverage such as income and employment, as well as less commonly used but important variables of risk aversion and political affiliation.

As we have demonstrated, it is remarkable that the association of these variables with people's insurance decisions are of the same order of magnitude as standard demographic determinants, such as education and employment status.

The fact that both financial and health insurance literacy were associated with having insurance seems likely to stem from the greater comfort level that more knowledgeable individuals probably have with making health insurance decisions. Those with low health insurance literacy, who answered fewer than 3 of 7 questions correctly, were especially unlikely to have insurance coverage, potentially because they lack experience with the health care system. Because the ACA relies on consumer choice, those who are 
TABLE 3. Characteristics Associated With Coverage and Selection of Health Insurance for Full Sample

\begin{tabular}{|c|c|c|c|c|c|}
\hline & \multirow{3}{*}{$\begin{array}{c}\text { Any Coverage } \\
\text { Logit }(95 \% \mathrm{CI}) \\
(\mathrm{n}=\mathbf{2 7 4 2})\end{array}$} & \multicolumn{4}{|c|}{ Type of Coverage Selected } \\
\hline & & \multicolumn{4}{|c|}{ Multinomial Logit $(95 \%$ CI) $(n=2742)$} \\
\hline & & $\begin{array}{l}\text { Medicaid } \\
(\mathrm{n}=274)\end{array}$ & $\begin{array}{l}\text { Marketplace } \\
(n=148)\end{array}$ & $\begin{array}{c}\text { ESI } \\
(n=1582)\end{array}$ & $\begin{array}{l}\text { All Other } \\
(n=460)\end{array}$ \\
\hline \multicolumn{6}{|l|}{ Literacy } \\
\hline High financial literacy & $1.598(1.142-2.234)^{* * *}$ & $1.697(1.056-2.725)^{* *}$ & $2.140(1.381-3.316)^{* * *}$ & $1.382(0.940-2.032)^{*}$ & $1.599(0.997-2.564)^{*}$ \\
\hline High health insurance literacy & $1.537(1.221-1.933)^{* * *}$ & $1.853(1.352-2.540)^{* * *}$ & $1.987(1.146-3.447)^{* *}$ & $1.407(0.760-2.603)$ & $1.420(1.020-1.976)^{* *}$ \\
\hline Pseudo- $R^{2}$ & 0.3488 & 0.4008 & & & \\
\hline
\end{tabular}

uninsured and have low health insurance literacy represent a particularly vulnerable population; for them obtaining coverage may be especially difficult. Our findings are robust to alternative specifications using different health measures. It is thus unlikely that our findings for health insurance literacy solely reflect differences in health that are correlated with both the literacy measures and health insurance choices (online appendix Table 4, Supplemental Digital Content 6, http://links.lww.com/MLR/B316). Interestingly, the correlation between financial and health insurance literacy is low, suggesting that they may contribute to insurance coverage through slightly different mechanisms.

Our study has several limitations. First, our sample size was relatively small. Despite this, we find significant results. Second, our survey had a low cumulative response rate. The rate was on par, however, with other nationally representative surveys conducted by nongovernmental organizations that have provided early pictures of the impact of the ACA including others reported in this journal, ${ }^{8}$ and estimates from the ALP closely track administrative data. ${ }^{4}$ The trade-off for the small sample size and low response rate was access to data on financial and health insurance literacy-variables that are usually lacking in data from federal surveys with larger sample sizes and higher cumulative response rates. Third, we relied on survey data, which may be biased due to sample selection or self-reporting. But this does not necessarily distort the accuracy of findings: The ALP provided highly accurate predictions in the 2012 presidential elections, for example. ${ }^{17}$

We focus on 2 points in time and thus in this work did not distinguish between those who experienced 1 or multiple health insurance transitions. Health insurance and financial literacy might also contribute to maintaining consistent insurance coverage over this period.
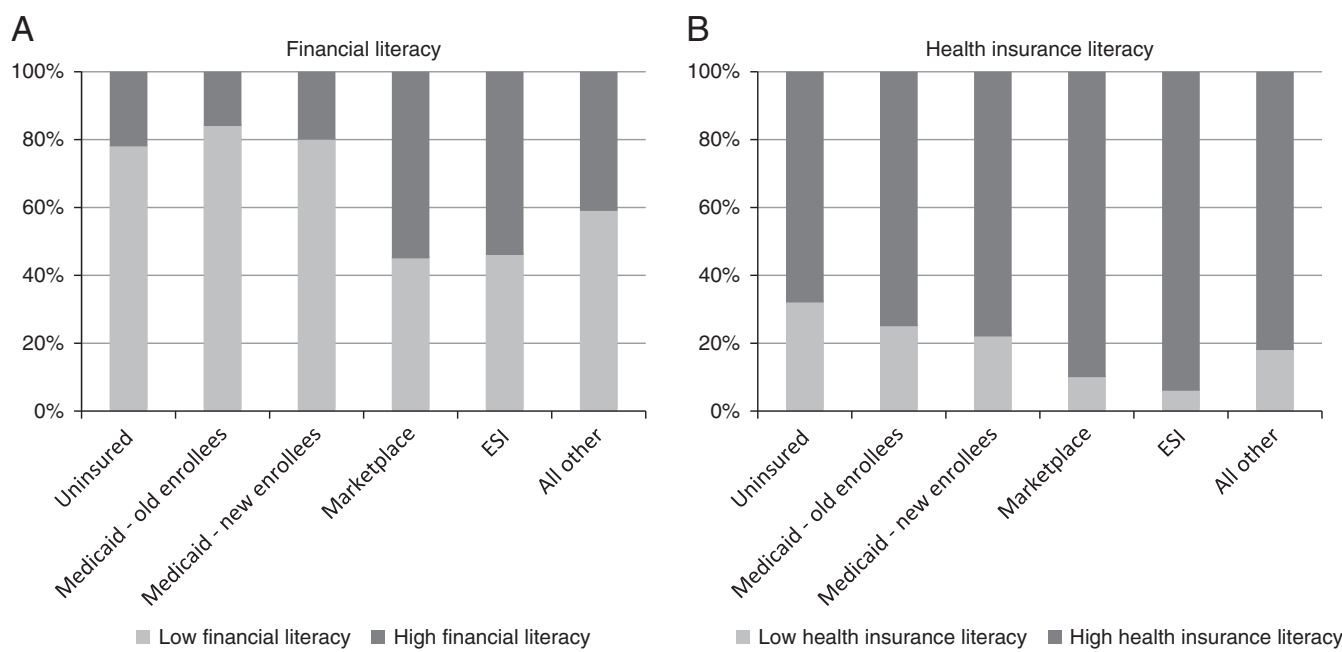

FIGURE 2. Financial and health insurance literacy by type of health insurance coverage in spring 2015. A, Financial literacy. B, Health insurance literacy. The share of individuals having low or high levels of literacy by type of health insurance coverage in spring $2015(n=2742)$. Source: RAND American Life Panel, individuals aged 18-64. ESI indicates Employer Sponsored Insurance. 
Understanding which factors affect an individual's decision to get health insurance and to enroll via Medicaid versus the Marketplaces versus other channels can help to inform health policy and better target and design outreach and consumer education programs. Our findings suggest that the impediments to obtaining coverage go beyond the primarily sociodemographic ones which have been established as contributing to gaps in coverage. In that light, policies and programs designed to further reduce the numbers of uninsured - especially through Medicaid and the Marketplaces - should take into account not just ethnicity, employment status, and income, but levels of financial literacy and health insurance literacy. Although we cannot exclude that our results on the literacy measures may be - at least partly - capturing the influence of third factors which we cannot observe, the results still suggest that low financial and health insurance literacy predict remaining uninsured. Limited health insurance and financial literacy may make it difficult for consumers to assess whether insurance premiums are "worth it." Any programs designed to further decrease the number of uninsured adults should take into account that these individuals may have low health insurance and financial literacy. Whether changes to the federal healthcare.gov Marketplace designed to simplify decision making during the 2016 open enrollment period will be enough to help these groups gain coverage remains an open question.

\section{ACKNOWLEDGMENTS}

The authors thank Susan Bohandy PhD for her comments on the manuscript and the ALP Technical Team.

\section{REFERENCES}

1. Sommers BD, Musco T, Finegold K, et al. Health reform and changes in health insurance coverage in 2014. $N$ Engl J Med. 2014;371:867-874.

2. Collins SR, Rasmussen PW, Doty MM. Gaining Ground: Americans' Health Insurance Coverage and Access to Care After the Affordable Care Act's First Open Enrollment Period. New York, NY: Commonwealth Fund; 2014. Available at: www.commonwealthfund.org/publications/issue-briefs/ 2014/jul/health-coverage-access-aca. Accessed October 24, 2016.

3. Long SK, Karpman M, Shartzer A, et al. Taking Stock: Health Insurance Coverage Under the ACA as of September 2014. Washington, DC: Urban Institute; 2014. Available at: http://hrms.urban.org/briefs/ Health-Insurance-Coverage-under-the-ACA-as-of-September-2014.html. Accessed October 24, 2016.

4. Carman KG, Eibner C, Paddock SM. Trends in health insurance enrollment, 2013-15. Health Aff. 2015;34:1044-1048.

5. Vistnes J, Cohen SB. Transitions in health insurance coverage over time, 2012-2014 (selected intervals): estimates for the US civilian noninstitutionalized adult population under the age 65. Statistical brief no. 467. Rockville, MD: Agency for Healthcare Research and Quality; 2015.

6. Witters D. In US, uninsured rates continue to drop in most states. Washington, DC: Gallup; 2015. Available at: www.gallup.com/poll/184514/ uninsured-rates-continue-drop-states.aspx. Accessed October 24, 2016.

7. Smith JC, Medalia C. Health insurance coverage in the United States: 2014. US Census Bureau Report P60-253. 2015. Available at: www.census.gov/ content/dam/Census/library/publications/2015/demo/p60-253.pdf. Accessed October 24, 2016.

8. Sommers BD, Gunja MZ, Finegold K, et al. Changes in self-reported insurance coverage, access to care, and health under the Affordable Care Act. JAMA. 2015;314:366-374.

9. Van Rooij M, Lusardi A, Alessie R. Financial literacy and stock market participation. J Financ Econ. 2011;101:449-472.

10. Lusardi A, Mitchell OS. Financial literacy and retirement planning in the United States. J Pension Econ Financ. 2011;10:509-525.
11. Lusardi A, de Bassa Scheresberg C. Financial literacy and high-cost borrowing in the United States. National Bureau of Economic Research, Working Paper 18969. 2013

12. Cutler DM, Finkelstein A, McGarry K. Preference heterogeneity and insurance markets: explaining a puzzle of insurance. Am Econ Rev Pap Proc. 2008;98:157-162.

13. Barcellos SH, Wuppermann AC, Carman KG, et al. Preparedness of Americans for the Affordable Care Act. Proc Natl Acad Sci U S A. 2014;111:5497-5502.

14. DiJulio B, Firth J, Brodie M. California's Previously Uninsured After The ACA's Second Open Enrollment Period. Washington, DC: Kaiser Family Foundation; 2015. Available at: http://kff.org/health-reform/ report/californias-previously-uninsured-after-the-acas-second-open-enroll ment-period/. Accessed October 24, 2016

15. King M, Ruggles S, Alexander JT, et al. Integrated Public Use Microdata Series, Current Population Survey: Version 30 (Machine-readable Database). Minneapolis, MN: Minnesota Population Center; 2010.

16. Carman KG, Eibner C. Insurance transitions following the first ACA Open Enrollment Period. RAND Research Report RR-948-RC. 2015. Available at: www.rand.org/pubs/research_reports/RR948.html. Accessed October 24, 2016.

17. Gutsche TL, Kapteyn A, Meijer E, et al. The RAND continuous 2012 presidential election poll. Public Opin Q. 2014;78(S1):233-254.

18. Department of Health and Human Services, Office of the Assistant Secretary for Planning and Evaluation. Health Insurance Marketplaces 2015 Open Enrollment Period: March Enrollment Report. Washington, DC: HHS; 2015. Available at: http://aspe.hhs.gov/health/reports/2015/MarketPlaceEnroll ment/Mar2015/ib_2015mar_enrollment.pdf. Accessed October 24, 2106.

19. Centers for Medicare and Medicaid Services. Medicaid and CHIP: December 2014 Monthly Applications, Eligibility Determinations and Enrollment Report. Baltimore, MD: CMS; 2015. Available at: https:// www.medicaid.gov/medicaid/program-information/downloads/december2014-enrollment-report.pdf. Accessed October 24, 2016.

20. Barcellos SH, Wuppermann AC, Carman KG, et al. Preparedness of Americans for the Affordable Care Act. Proc Natl Acad Sci USA. 2014;111:5497-5502.

21. Heiss F, McFadden D, Winter J. Who failed to enroll in Medicare Part D, and why? Early results. Health Aff (Project Hope). 2006;25:5.

22. Bhargava S, Loewenstein G, Sydnor J. Do individuals make sensible health insurance decisions? Evidence from a menu with dominated options. NBER Working paper \#21160, 2015. Available at http:// www.nber.org/papers/w21160. Accessed October 24, 2016.

23. Baicker K, Congdon WJ, Mullainathan S. Health insurance coverage and take-up: lessons from behavioral economics. Milbank Q. 2012;9:107-134.

24. Liebmann J, Zeckhauser R. Simple humans, complex insurance, subtle subsidies. 2008. NBER Working Paper No. 14330.

25. Dohmen T, Falk A, Huffman D, et al. Individual risk attitudes: measurement, determinants, and behavioral consequences. J Eur Econ Assoc. 2011;9:522-550.

26. De Meza D, Webb D. Advantageous selection in insurance markets. RJE. 2001;32:249-262.

27. Kaiser Family Foundation. Kaiser Health Tracking Poll: April 2015. Washington, DC: Kaiser Family Foundation. 2015. Available at: http:// $\mathrm{kff}$.org/health-reform/poll-finding/kaiser-health-tracking-poll-april-2015/. Accessed October 24, 2016.

28. Hamel L, Norton M, Brodie M, et al. Data Note: Predictors of Positive and Negative Attitudes Towards the ACA Among Non-group Insurance Enrollees. Washington, DC: Kaiser Family Foundation; 2015. Available at: http://kff.org/health-reform/poll-finding/data-note-predictors-ofpositive-and-negative-attitudes-towards-the-aca-among-non-group-insuranceenrollees/. Accessed October 24, 2016.

29. Blendon RJ, Benson JM. Voters and the Affordable Care Act in the 2014 Election. N Engl J Med. 2014;371:e(31)1-e(31)7.

30. Newport F. Politics affect uninsured Americans' insurance intentions. Gallup. 2014. Available at: www.gallup.com/poll/168143/politics-affectuninsured-americans-insurance-intentions.aspx. Accessed October 24, 2016.

31. Sommers BD, Maylone B, Nguyen KH, et al. The impact of state policies on ACA applications and enrollment among low-income adults in Arkansas, Kentucky, and Texas. Health Aff. 2015;34:1010-1018.

32. StataCorp. Stata Statistical Software: Release 14. College Station, TX: StataCorp LP; 2015. 